REVISTA X, Curitiba, volume 12, n.3, p.178-193,2017.

\title{
PROFESSOR QUANTO MAIS CEDO É MELHOR? O PAPEL DIFERENCIAL DA EDUCAÇÃO BILÍNGUE
}

\section{Teacher, the earlier the better? The distinctive role of bilingual education}

\author{
Ricardo Santos DAVID - FCU ${ }^{1}$
}

\begin{abstract}
RESUMO: O objetivo deste estudo é mostrar a importância da educação bilíngue no desenvolvimento infantil. Observamos, em nossa sociedade, um crescente aumento pela procura por cursos de língua inglesa para crianças desde a primeira infância, sustentado por um argumento que circula de maneira transparente como uma verdade estabilizada: o do "quanto mais cedo, melhor". A metodologia adotada é uma pesquisa bibliográfica. Os resultados deste estudo evidenciam que a educação bilíngue precoce é favorável ao desenvolvimento cognitivo das crianças. Foi demonstrado o efeito positivo do bilinguismo sobre o funcionamento intelectual em relação ao monolinguismo, desde que a criança tenha sido exposta a certa quantidade de exposição bilíngue o mais cedo possível. O efeito bilinguismo precoce será maior em bilíngues que começaram ativamente a utilização de mais do que uma língua cedo na vida. Esta hipótese está de acordo com a volumosa literatura que abordam os efeitos de aquisição precoce no campo da linguagem e desenvolvimento da alfabetização.
\end{abstract}

Palavras - chaves: Ensino; Bilinguismo; Alfabetização; Benefícios.

\begin{abstract}
The objective of these studies is to show the importance of bilingual education in child development. The methodology is a literature search. We notice, in our society, a rising increase on the search for English language courses for children, since early childhood, sustained by an argument which circulates in a "transparent" way as an established true: "the sooner, the better". The results of this study show that early bilingual education is conducive to cognitive development of children. It has been shown the positive effect of bilingualism on intellectual functioning in relation to monolingualism, since the child has been exposed to a certain amount of bilingual exposure as soon as possible. Early bilingual effect will be greater in bilingual actively started to use more than one language early in life. This hypothesis is in accordance with the voluminous literature addressing the effects of early acquisition in the field of language and literacy development
\end{abstract}

Keywords: education; Bilingualism; Literacy; Benefits.

\footnotetext{
${ }^{1}$ Pós-doutorado em Educação pela FCU - Florida Christian University / EUA. Doutorado em Educação pela Uniatlantico Espanha; Mestrado em Educação pela mesma instituição. Especialista em Linguística e Literatura; professor, pesquisador e revisor de textos.
} 


\section{INTRODUÇÃO}

Estudos apontam que alunos bilíngues apresentam ganhos cognitivos, mas o diálogo entre as línguas ainda é delicado na alfabetização. A educação bilíngue também tem sido objeto de outros estudos no campo da educação, tendo como foco não apenas as capacidades que ajuda a desenvolver, mas os âmbitos em que a própria linguagem atua em especial no contexto escolar formal.

Paralelamente a esse surgimento e crescimento de cursos de línguas no Brasil, ocorre o ensino bilíngue, o qual começou a se expandir no país há não mais que três décadas, de acordo com Moura. Nesse tipo de escola, há o ensino de e em duas línguas desde as séries iniciais da educação escolar. Essas escolas seguem o calendário e diretrizes nacionais. Segundo reportagem do jornal O Estado de São Paulo, em 2009 havia 180 escolas bilíngues em todo o Brasil. Os alunos são alfabetizados antes em Português e depois na segunda língua, para possibilitar o bilinguismo desde cedo, sendo metade das aulas ministradas em Português e a outra metade na outra língua, majoritariamente o inglês, podendo esta proporção variar, chegando até mesmo à exclusividade do ensino em língua estrangeira. O ensino bilíngue enfrentou barreiras para se firmar como proposta pedagógica em todo o mundo, sendo até mesmo apontado como o fator determinante do insucesso acadêmico de crianças nos Estados Unidos. A escola inclui o ensino bilíngue na infância porque ela sabe que a prioridade é preparar a criança para a vida adulta e dialogar em diferentes contextos e novos exames acadêmicos.

Mas se as pesquisas hoje sobre educação bilíngue derrubaram o mito de que ensinar dois idiomas confunde as crianças, há um momento em que o diálogo entre as línguas é mais delicado: na alfabetização, período em que a criança passa pelo processo de aprendizagem dos processos de codificação e decodificação da língua escrita. Quando a criança ingressa no ensino bilíngue, a escola deve tomar alguns cuidados como escolher em qual dos dois idiomas vai introduzir a leitura e a escrita - ou se vai alfabetizar nas duas línguas ao mesmo tempo. Há uma explicação em que há três tipos de alfabetização: a sequencial materna-segunda língua, a sequencial na segunda língua seguida da materna, e a simultânea, na qual ambos os idiomas são ensinados. Ainda que a opção pela alfabetização sequencial seja mais confortável, pois o desenvolvimento da por uma segunda língua vem de forma natural à criança que fala duas línguas já está 
fazendo hipóteses de como vai fazer isso na segunda língua sem ter grandes dificuldades.

A busca pelo aprendizado de uma língua estrangeira, geralmente o inglês, por crianças a partir de 3 anos (ou até mesmo antes dessa idade) é um movimento recente. Sustentada pelo argumento do "quanto mais cedo, melhor", esta prática tem se tornado cada vez mais frequente na sociedade brasileira, o que gerou o aumento pela procura por cursos infantis de língua inglesa em escolas de línguas, escolas bilíngues ou em escolas internacionais. Esta mesma procura também sustentou a expansão e a disseminação de diversas escolas de línguas, assim como o surgimento de novos cursos que atendessem a esta demanda e a este público em específico.

$\mathrm{O}$ argumento do "quanto mais cedo, melhor" faz-se constante no ensino sobre o ensino de língua inglesa para as crianças, indicando-nos um discurso a ser analisado. Este argumento circula com valor de verdade absoluta, e de nosso ponto de vista, sustenta esta prática de ensino sem que seja necessária a explicitação daquilo que o sustenta - um discurso. Procuramos justamente compreender que discurso(s) é (são) este(s) que sustenta(m) a evidência deste argumento: quanto mais cedo, melhor.

Pode-se afirmar ainda que, por se dar quase que exclusivamente na rede particular, o ensino infantil de língua inglesa estaria aliado aos sentidos de consumo, transformando alunos em clientes e o aprendizado em mercadoria. Além disso, as crianças seriam vistas pelas escolas que oferecem tais cursos e pelos pais que as matriculam. Nesses, como futuros trabalhadores que devem se preparar para o mercado de trabalho, qualificando-se para nele atuar.

Acreditamos que esta pesquisa tenha relevância, uma vez que, diante deste quadro de expansão dos cursos infantis de língua inglesa, uma análise discursiva de suas injunções pode auxiliar educadores da área a repensarem suas práticas, seus métodos e seus objetivos para este ensino. Pode também ser uma consideração relevante para que políticas públicas sejam criadas para regularizar esta categoria de ensino, uma vez que, o ensino infantil de língua inglesa não tem nenhum tipo de legislação que normatize suas práticas, além de configurar-se como fator de discriminação e exclusão daqueles que não têm acesso a este consumo, já que o Estado não oferece este ensino nas escolas públicas, ou seja, limita seu acesso a grupos mais elitizados, e permite, ao mesmo tempo, que as escolas particulares o ofereçam como forma de diferenciação. 
A aprendizagem e a aquisição da segunda língua vêm se tornando um tema de investigação científica por se tratar de um dos aspectos que estão relacionados ao sucesso profissional do indivíduo dentro do paradigma da globalização. O estudo do bilinguismo tem sido explorado visando ampliar os conhecimentos nesta área a fim de superar as falhas e dificuldades, para promover o aprendizado com qualidade.

A construção simbólica e imaginária da importância que o inglês tem em nossa sociedade atual globalizada, sendo ele próprio a língua da globalização, é inegável. Garante ao inglês o título de língua global, ou língua franca, ou seja, aquela que vai ter um papel de destaque em países, seja como língua oficial ou como língua oficial adjunta, seja por ser a escolhida como língua estrangeira a ser estudada, o que confere à língua um grande número de falantes nos mais variados países, como já mostrado pelos números trazidos anteriormente.

Um crescente corpo de pesquisas sugere que os indivíduos bilíngues superam monolíngues em uma variedade de tarefas cognitivas (BIALYSTOK, 2008) (CARLSON; MELTZOFF, 2008) (COSTA et al, 2008). Estas vantagens, que foram caracterizadas como vantagens no controle cognitivo, têm sido documentadas ao longo da como na pesquisa. A melhora cognitiva entre crianças pré-escolares expostas precocemente ao bilinguismo (KOVACS; MEHLER, 2009,) (POULIN-DUBOIS et al, 2011) ( YOSHIDA et al , 2011), (ANTES ;MACWHINNEY de 2010 ).

Este artigo tem por finalidade mostrar importância da educação bilíngue no desenvolvimento infantil. A parte inicial deste artigo aborda a definição de bilinguismo na concepção de diversos autores. Em seguida discute-se o tema educação bilíngue, abordando sua importância. Na parte final, busca-se refletir se a aquisição de uma segunda língua por crianças é prejudicial ou favorável ao seu desenvolvimento e também inter-relação entre alfabetização e bilinguismo.

Para a elaboração deste estudo foi adotado o método de revisão bibliográfica. Buscou-se construir o conhecimento científico embasado em fontes de dados (livros, artigos científicos, monografias e teses) que abordam o tema (GIL, 2002). A proposta é apresentar um estudo bibliográfico com argumentação de autores neste assunto específico que é a educação bilíngue na infância.

Para o desenvolvimento desta pesquisa foi realizada a coleta de dados secundários. Segundo Yin (2005) dados secundários serão levantados por meio de uma revisão bibliográfica para a realização da fundamentação teórica desta pesquisa. Assim, 
o acesso aos dados foi por meio da web, se constituindo de artigos, teses, dissertações científicas publicados sobre a temática. O tratamento dos dados deu-se por meio da abordagem qualitativa.

\section{BILINGUISMO E EDUCAÇÃO BILÍNGUE}

A primeira ideia que noção de bilinguismo sugere parece simples: é de que uma pessoa fala duas línguas. Essa definição é mesma que aparece no dicionário Aurélio(Ferreira, 1988:95), em que o bilíngue é aquele que tem duas línguas. Que fala duas línguas. No dicionário de Linguagem e Linguística (Trask, 2004:47 - 48), a definição de bilinguismo também á apresentada como a capacidade de falar duas línguas. Neste último caso as variações da própria comunidade determinam a função de cada língua. Conhecer as definições sobre bilinguismo na perspectiva de diversos autores contribui para compreender a aprendizagem e a aquisição da segunda língua. Foi a partir do século XX que se buscou definir o bilinguismo com maior precisão. Hornby $(1977$, p.8) explica que o bilinguismo trata-se de:

Situação linguística em que duas línguas coexistem na mesma comunidade ou em que um indivíduo apresenta competência gramatical e comunicativa em mais do que uma língua. O bilinguismo costuma ser considerado como um contínuo linguístico, situado entre dois extremos teóricos, o de competência mínima e o de competência nativa.

Na concepção de Perri (2013) o bilinguismo é concebido como sendo a capacidade do indivíduo de estabelecer comunicação em duas línguas distintas, de forma alternada, sendo capaz de escrever, ler, entender e falar, com controle quase total, duas línguas.

Em seu estudo sobre "Bilinguismo e Educação Bilíngue", Megale (2005, p.2) assevera que "bilíngue é o indivíduo que possui competências mínimas em falar, ouvir, ler e escrever em uma língua diferente de sua língua nativa". Na concepção de MyersScotton (2006 apud Salgado et al, 2009, p.3)

Falar somente uma língua, tipicamente a língua que se adquire como sua primeira língua ou 'língua materna' (geralmente a língua falada em casa, pela família) é chamado de monolinguismo. Bilinguismo é o termo usado para a situação em que o indivíduo fala duas ou mais línguas.

Cañete (2008) embasado na teoria de Appel e Muysken (1996) preconiza que o bilingusimo se refere à pessoa que é capaz de aplicar duas ou mais línguas, sendo que, 
além disso, deve saber ouvir, falar, compreender e ler em uma segunda língua. Conforme Megale (2005) os estudos sobre bilinguismo devem considerar os seguintes aspectos:

- Grau de proficiência: o conhecimento do indivíduo sobre as línguas em questão deve ser avaliado.

- A função e o uso das línguas: situações, nas quais o indivíduo faz uso das duas línguas, também devem ser objeto de estudo ao conceituar o bilinguismo.

- Alternância de código: deve ser estudado como e com qual frequência e condições o indivíduo alterna de uma língua para outra.

- Fenômeno da interferência: deve ser estudado, como uma língua influencia a outra e como uma interfere na outra.

Para Salgado et al (2009) admite-se que o bilinguismo, reconhece como bilíngue, aqueles que conseguem compreender ou produzir enunciados falados ou escritos em qualquer grau em mais de uma língua. Desta forma, os indivíduos que podem ler uma segunda língua, porém, não sabem falar essa língua, também podem ser considerados como bilíngues, pois, são consideradas como tendo competência receptiva numa segunda língua. Isto significa que não são monolíngues, pois, estes possuem habilidade receptiva ou subtraída onde o que predomina é política do país; exemplo de outros imigrantes que entram nos EUA ou Inglaterra para aperfeiçoar uma segunda língua. produtiva somente em sua língua materna.

\section{EDUCAÇÃO BILÍNGUE}

A aquisição da primeira língua, a língua materna, é feita de modo natural. O inatismo, como é denominado, é o meio segundo o qual a criança é exposta ao input e desenvolve a linguagem. A criança aprende a sintaxe de sua língua de forma natural, sem ter a necessidade de ser ensinada (CHOMSKY, 1977).

O inatismo defendido por Chomsky de uma teoria da aprendizagem pressupõe a existência de estruturas relacionada a mecanismos cerebrais e às capacidades cognitivas, ou seja, o conjunto de capacidades cognitivas humanas possui uma estrutura fundamental determinada biologicamente, que mantém estreita relação com a capacidade linguística (SELL, 2002).

Mello (2010, p.128) relata que: 
A educação bilíngue está diretamente relacionada à história, à ideologia e à organização sociopolítica de um povo e, por isso, segue caminhos diferentes. São esses diversos caminhos que deram origem aos diferentes modelos e tipos de programas de ensino bilíngue que focalizamos a seguir

É através da Gramática Universal, que o indivíduo seleciona códigos e de desencadeantes do sistema linguístico da língua materna. Na visão inatista de Chomsky todo indivíduo já nasce geneticamente provido com uma gramática onde se encontram todas as regras possíveis da todas as línguas, ou seja, uma gramática universal. Nesta perspectiva o indivíduo realiza operações mentais que transforma a gramática universal na gramática da língua a que está exposta (CAÑETE, 2008). Silva $(2011$, p.4) afirma que:

Segundo a visão inatista da linguagem, criança detém certa gramaticalidade da sua língua materna, é isso que a faz ser capaz de gerar sentenças de acordo com as regras vigentes da sua língua, mesmo que jamais tenham sido ouvidas daquela maneira, desenvolvendo assim uma característica que sempre esteve presente em sua mente, ou seja, o processo da gramática gerativa transformacional.

Assim sendo, quando a criança passa a incorporar como modelo algumas estruturas da língua mãe, não é que tenha ocorrido imitação, mas sim por que ocorreu a incorporação de novos modelos de regras para sua língua. Uma das razões pelas quais o estudo da aquisição de uma segunda língua é tão intrigante diz respeito ao fato de que o resultado desta aquisição (diferentemente do resultado de aquisição de L1) é comprovadamente diverso entre os adultos. Os pesquisadores tentam, então, entender qual o efeito que a idade de aquisição exerce nesse resultado. De acordo com Birdsong (2006), a maioria das pesquisas empíricas sobre a questão da idade em L2, realizadas nos últimos 20 anos, tem se focado sobre o estado final da L2, tendo em vista que é a evidência desse estado que determina os maiores limites de aquisição.

A educação bilíngue pode ser aplicada a diferentes contextos e diferentes tipos de alunos. Existem diversas variações de programas, os quais são denominados de imersão, sendo: educação bilíngue transicional ou educação bilíngue de manutenção (educação bilíngue compensatória ou assimilacionista/segregacionista/imersão estruturada), educação bilíngue desenvolvimental (educação de língua abrigada), manutenção pluralística ou de grupo (MELLO, 2010).

De acordo com Mello (2010, p.120): 
A própria expressão educação bilíngue tem sido usada de maneira abrangente para caracterizar diferentes formas de ensino nas quais os alunos recebem instrução (ou parte da instrução) numa língua diferente daquela que normalmente eles usam em casa. Vários são os modelos e tipos de educação bilíngue. Eles, porém, diferem quanto aos objetivos, às características dos alunos participantes, à distribuição do tempo de instrução nas línguas envolvidas, às abordagens e práticas pedagógicas, entre outros aspectos do uso das línguas e do contexto em que estão inseridos.

É importante esclarecer que no Brasil, a educação bilíngue está relacionada à educação indígena ou às línguas inglesas, francês, e espanhol que possuem prestígio internacional, sendo denominada de educação bilíngue de elite (MELLO, 2010).

\section{A AQUISIÇÃO PRECOCE DE UMA SEGUNDA LÍNGUA POR CRIANÇAS: PREJUDICIAL OU FAVORÁVEL?}

Nos dias atuais há uma preocupação por parte dos pais e de professores se o bilinguismo pode afetar a cognição e o desenvolvimento da linguagem na infância. Cabe ressaltar que durante décadas vários estudos foram desenvolvidos sobre a educação bilíngue, sendo que inicialmente havia o pensamento de que o bilinguismo era nocivo para o desenvolvimento infantil (SANTOS, 2013).

Nos anos 60 foram desenvolvidos os programas no Canadá para imersão francesa de crianças que falavam a língua anglo-fônicas. Foi a partir disto, que buscouse uma nova compreensão sobre os resultados da educação bilíngue para crianças (SANTOS, 2013). Em 1962 Elizabeth Peal e Wallace Lambert realizaram diversos testes escolares, em que foi demonstrada a superioridade geral de bilíngue em comparação com o monolíngue (BIALYSTOK, 2011) (MARTINS, 2007).

$\mathrm{O}$ debate atual sobre o bilinguismo abarca o questionamento se a aprendizagem da segunda língua deverá ser o quanto mais cedo, ou seja, o mais precoce possível. Desta forma, a compreensão sobre os efeitos do bilinguismo no desenvolvimento cognitivo da criança tem sido o enfoque de muitas pesquisas científicas, contudo também tem se mostrado uma tarefa árdua. Nos relatos da literatura ainda existem muitas contradições acerca dos benefícios do início da educação bilíngue muito precoce (NOBRE; HODGES, 2010).

Numa perspectiva histórica a educação bilíngue foi considerada nociva para o desenvolvimento cognitivo das crianças. Foram realizados estudos que demonstravam o 
bilinguismo estava associado com mudanças de personalidade, com baixo quociente intelectual e também com a confusão linguística. Diante disto, criou-se o mito de que a educação bilíngue precoce seria prejudicial para a criança. Aliado a isto, havia a falta de entendimento sobre questões culturais, sociais e econômicas que estavam envolvidas na pesquisa. Estes fatores que impediam o esclarecimento sobre as especificidades da cognição das crianças bilíngues (NOBRE; HODGES, 2010).

Segundo Nobrega e Hodges (2010, p.6) as principais vantagens do bilinguismo são:

[...] relacionamento com pais, família e amigos. comunicação com pessoas de outras nacionalidades e etnias; sensibilidade para línguas e comunicação; maior conhecimento cultural e com isso maior visão de mundo, entre outros.

Em seu estudo sobre bilinguismo na infância, Bialystok (2008) questiona se este é bom, mau ou indiferente. Para responder a este questionamento, a autora relata que há evidências crescentes de que várias experiências têm um efeito significativo sobre o desenvolvimento comportamental, neuropsicológico e aspectos estruturais do desempenho cognitivo dos indivíduos, pois, conexões neurais podem ser modificadas. Estas mudanças estruturais acarretadas pela experiência também é observada em pessoas que falam uma segunda língua, pois, foi demonstrado que têm aumento da densidade de matéria cinzenta (conexões neurais) no lado esquerdo inferior do córtex parietal língua (MECHELLI et al., 2004).

Bialystok (2008) lembra que esta mudança de estrutura é mais evidente em bilíngues precoces e aqueles com maior proficiência na segunda língua. Estudos de neurociência e aprendizagem demonstram que esta região é sensível à aquisição de vocabulário monolíngues e bilíngues (GREEN et al, 2007). A experiência tem um efeito poderoso no desempenho cognitivo, estrutura e organização do cérebro, e o bilinguismo é uma dessas experiências que influencia em resultados cognitivos positivos (BIALYSTOK, 2008).

Conforme Struys (2013) uma das características mais marcantes do processamento da linguagem do ser humano é a capacidade para acomodar dois ou mais idiomas em um cérebro. Isto aumenta a flexibilidade linguística porque permite se adaptar a uma ampla gama de situações comunicativas. 
Em estudo recente sobre os impactos do bilinguismo para o desenvolvimento infantil Yang e Yang (2016) investigaram a influência do aprendizado da segunda língua sobre o sistema de atenção em um grupo de crianças, jovens e adultos linguística e culturalmente homogêneos. As crianças tinha faixa etária de 5 a 6 anos. Foram observados efeitos bilíngues vantajosos sobre a atenção nos níveis de processamento globais de eficiência, tempo de resposta e precisão em uma magnitude mais pronunciada em crianças do que em jovens e adultos.

De acordo com Ferronatto e Gomes (2008, p.4) explicam que:

\begin{abstract}
O desenvolvimento da linguagem bilíngue em crianças pré-escolares pode divergir do desenvolvimento monolíngue em aspectos superficiais, mas fundamentalmente os processos são idênticos. As crianças bilíngues empregam as mesmas estratégias de aquisição que as crianças monolíngues, sendo, porém, capazes de utilizar seus sistemas linguísticos em desenvolvimento de maneira diferenciada sob o ponto de vista contextual.
\end{abstract}

Com base em evidências anteriores mostrando um efeito benéfico do bilinguismo no desenvolvimento cognitivo das crianças, Bialystok et al (2012) realizaram um estudo para examinar os efeitos do bilinguismo na cognição e explorar possíveis mecanismos para estes efeitos. Esta pesquisa mostrou que o bilinguismo tem um papel relevante na proteção contra o declínio cognitivo. Discute-se a evidência recente que bilinguismo está associado com um atraso no aparecimento de sintomas de demência.

Flory e Souza (2014, p.7) expõem em seu estudo que as principais vantagens do bilinguismo precoce são:

a) mostram vantagens consistentes em tarefas envolvendo habilidades verbais e não-verbais; b) mostram habilidades metalinguísticas avançadas, especialmente manifestadas em seu controle sobre o processamento da língua; c) as vantagens cognitivas e metalinguísticas aparecem em situações bilíngues que envolvem o uso sistemático das duas línguas (como a aquisição simultânea ou a educação bilíngue); d) os efeitos positivos do Bilinguismo aparecem relativamente cedo no processo de tornar-se bilíngue e não requerem alto nível de proficiência, nem que se tenha alcançado o Bilinguismo Balanceado.

Se o bilinguismo tem um efeito positivo sobre o funcionamento intelectual e relação ao monolinguismo, espera-se que certa quantidade de exposição bilíngue seja necessária para observar a vantagem assumida (PAAP; GREENBERG, 2013). Logicamente, esta diferença dependerá da idade inicial de exposição a várias línguas. $\mathrm{O}$ 
efeito bilinguismo precoce será maior em bilíngues que começaram ativamente a utilização de mais do que uma língua cedo na vida. Esta hipótese está de acordo com a volumosa literatura que abordam os efeitos de aquisição precoce no campo da linguagem e desenvolvimento da alfabetização (KOVELMAN et al, 2008) (SUNDARA et al, 2006) ( UCCELLI ; PÁEZ, 2007).

Diante de pesquisas realizadas constata-se que existem muitos argumentos favoráveis para expor a criança à educação bilíngue o quanto mais cedo possível. Aliado a isto existe também a crescente número de crianças que estão se desenvolvendo em contexto bilíngue, inclusive na escola, por exigência curricular. Contudo ainda existe também receio de que o bilinguismo provoque conflitos no processo de escolarização e, desta forma acabe sendo prejudicial para a criança. Em face disto se torna necessário produzir mais conhecimento acerca da influência do aprendizado precoce de uma segunda língua para o desenvolvimento da cognição infantil, e também discutir a relação entre alfabetização e bilinguismo.

\section{ALFABETIZAÇÃO E BILINGUISMO}

A aquisição de uma segunda língua pode se dar em um ambiente formal ou não. No contexto escolar a criança aprenderá uma nova língua por meio de instrução em sala de aula. No meio institucional a aprendizagem de uma segunda língua pode ser mesclada com a aprendizagem da linguagem escrita, qual seja, a alfabetização.

No contexto formal, o ensino da segunda língua integrado à alfabetização os conteúdos e tarefas é feito no sentido de expor a criança a situações reais de comunicação em segunda língua (DORNELAS, 2011). Cañete (2008, p.18) afirma que:

\footnotetext{
Em contextos formais na sala de aula normalmente é regulada a quantidade de input a ser exposto o estudante, mas há casos autodidatas em que o sujeito adquire a segunda língua por meio de materiais específicos.
}

No espaço escolar o processo de aquisição da linguagem é realizado gradualmente, se constituindo a base simbólica essencial para a criança se desenvolver, visando à promoção da construção de conhecimentos. Dessa forma tanto a linguagem quanto a e língua são pilares centrais em qualquer contexto educacional (LACERDA ET al, 2013). 
O documento recente do Ministério da Educação (MEC) sobre a educação bilíngue, explicita que de acordo com a 24. ${ }^{a}$ Declaração Universal dos Direitos Linguísticos, promovido pela UNESCO em Barcelona em 1996 "todas as comunidades linguísticas têm direito a decidir qual deve ser o grau de presença da sua língua, como língua veicular e como objeto de estudo, em todos os níveis de ensino no interior do seu território: pré-escolar, primário, secundário, técnico e profissional, universitário e formação de adultos"(THOMA et al, 2014).

O Referencial Curricular Nacional para a Educação Infantil (RCNEI) em relação à valorização de diferentes culturas no ensino infantil declara que: "conhecer algumas manifestações culturais, demonstrando atitudes de interesse, respeito e participação frente a elas e valorizando a diversidade (BRASIL, 1998). De acordo com a Organização das Escolas Bilíngues do Estado de São Paulo (OEBi, 2007):

\begin{abstract}
A proposta pedagógica das escolas bilíngues contempla uma maneira de educar que leva o aluno a interagir na prática com um contexto planetário, seguindo a tendência de globalização que espera da escola a formação de homens preparados para atuarem como cidadãos do mundo. O particular e o universal são trabalhados com bastante eficácia, inclusive, porque a barreira da língua já é ultrapassada no cotidiano de sala de aula.
\end{abstract}

Na perspectiva de Andreis-Witkosk (2013) o ensino do bilinguismo no ensino fundamental é importante, pois, a língua contribui para a formação identitária, sendo é decisiva para o desenvolvimento cognitivo das crianças e seu potencial de aprendizagem. Assim sendo, no contexto escolar os professores utilizam a língua oral, escrita e auditiva para promover o ensino do bilinguismo, buscando integrar todos os alunos neste processo de aprendizagem.

Salgado et al (2009) lembram que atualmente no Brasil, existem muitas escolas de ensino fundamental e médio que apresentam uma proposta bilíngue. Existem também muitos cursos livres de idiomas que buscam desenvolver a condição de bilíngues em seus alunos em um curto espaço de tempo. Com relação à formação do professor para o ensino do bilinguismo na educação infantil e no ensino fundamental.

Salgado et al (2009, p.4) advertem que:

Não basta hoje ter competência linguística somente para ensinar uma língua estrangeira ou uma segunda língua. O professor deve ser preparado para, além de lecionar "a" língua e "na" língua, ser um pesquisador de sua prática 
pedagógica. Idealmente, esse professor deve ser capacitado a investigar também as questões sociais e psicológicas que envolvem sua prática.

No que se refere à educação bilíngue na educação infantil nas escolas brasileiras, o que observa que em razão devido à grande expansão tecnológica e da comunicação mundial, surgiu a necessidade de se ter domínio com diferentes línguas, em especial a língua inglesa. Neste cenário cultural, social e econômico surge também a demanda pela aprendizagem de línguas nas escolas, para favorecer o ensino da segunda língua, sendo usada como meio de comunicação no decorrer do processo de ensino-aprendizagem, em conjunto com a alfabetização e letramento (FÁVARO, 2009).

\section{CONSIDERAÇÕES FINAIS}

Uma das principais características de uma escola bilíngue é que a criança não tem apenas aulas de inglês, mas também outras disciplinas na língua estrangeira. A proposta pedagógica desses programas é justamente que o inglês seja utilizado como meio de instrução para ensinar conteúdo de outras matérias, como matemática, estudos sociais, ciências, artes, educação física e culinária. Durante o decorrer das aulas, conteúdo e língua são trabalhados de maneira integrada, norteados pelo princípio de estimular a expressão livre do aluno. Desta forma, com o uso e construção natural do idioma, o aluno adquire de forma subconsciente a segunda língua.

Os resultados deste estudo evidenciam que a educação bilíngue precoce é favorável ao desenvolvimento cognitivo das crianças. Foi demonstrado o efeito positivo do bilinguismo sobre o funcionamento intelectual em relação ao monolinguismo, desde que a criança tenha sido exposta a certa quantidade de exposição bilíngue o mais cedo possível.

Conforme foi constatado neste estudo que o bilinguismo precoce é benéfico para o desenvolvimento cognitivo das crianças e que o ensino do bilinguismo no ensino fundamental é importante, pois a língua contribui para a formação identitária, sendo essa é decisiva para o desenvolvimento cognitivo das crianças e para potencial de aprendizagem.

A partir dos dados analisados na literatura verificou-se que o efeito bilinguismo precoce será maior em bilíngues que começaram ativamente a utilização de mais do que uma língua cedo na vida. Esta hipótese está de acordo com a volumosa literatura que 
abordam os efeitos de aquisição precoce no campo da linguagem e desenvolvimento da alfabetização

\section{REFERÊNCIAS BIBLIOGRÁFICAS}

APPEL, René, MUYSKEN, Pieter. Bilinguismo y contacto de lenguas. Barcelona: Ariel Lingüística, 1996.

BIALYSTOK, E. (2008). Bilingualism: the good, the bad, and the indifferent. Bilingualism Language Cogn.12 (1), 3-11.

BIALYSTOK, E et al. Bilingualism: consequences for mind and brain. Trends in Cognitive Sciences. Volume 16, Issue 4, April 2012, Pages 240-250.

BIALYSTOK, E. Aquisição do segundo idioma e bilinguismo na primeira infância e seu impacto sobre o desenvolvimento cognitivo inicial. In: Tremblay RE, Boivin M, Peters RDeV, eds. Enciclopédia sobre o Desenvolvimento na Primeira Infância [online]. Montreal, Quebec: Centre of Excellence for Early Childhood Development; 2011:1-5.

BIRDSONG, David. Age and second language acquisition and processing: a selective overview. Language Learning, v. 56, p. 9-49, 2006.

CAÑETE, Greici Lenir Reginatto. Educação bilíngue: uma experiência em Porto Alegre. Centro Universitário La Salle - Unilasalle. Canoas-RS, 2008. Disponível em: < http://biblioteca.unilasalle.edu.br/docs_online/tcc/graduacao/letras/2008/glrcanete.pdf >. Acesso em 10 de julho de 2016.

CHOMSKY, Noam. Reflexões sobre a linguagem. Lisboa: Edições 70, 1977.

COSTA A et al. On the bilingual advantage in conflict processing: Now you see it, now you don't. Cognition.2009.

DORNELAS, Andréia Lopes. Bilinguismo: contatos em conflito. Centro Universitário Adventista De São Paulo-Campus Engenheiro Coelho, Engenheiro Coelho, 2011. Disponível em: < https://getiunasp.files.wordpress.com/2013/09/tcc-bilinguismocontatos-em-conflito.pdf $>$. Acesso em 10 de julho de 2016.

FERRONATTO, Bianca Correia; GOMES, Erissandra. Um caso de bilinguismo: a construção lexical, pragmática e semântica. Rev. CEFAC, São Paulo, v. 10, n. 1, p. 22 28, Mar. 2008.

FLORY, Elizabete Villibor; SOUZA, Maria Thereza Costa Coelho de. Influências do Bilinguismo Precoce sobre o desenvolvimento Infantil: Vantagens, Desvantagens ou Diferenças? Revista Intercâmbio, volume XIX: 41 - 61 2009. São Paulo: LAEL/PUC-SP

GIL, A. C. Como elaborar projetos de pesquisa. São Paulo: Atlas, 2002.. 
GREEN, D. W. et al. Exploring cross-linguistic vocabulary effects on brain structures using voxel-based morphometry. Bilingualism: Language and Cognition, 10, 189-199, 2007.

HORNBY, Peter A. Dicionário de Termos Linguísticos, 1977. Disponível em: < http://www.ait.pt/recursos/dic_term_ling/dtl_pdf/B.pdf $>$. Acesso em 10 de julho de 2016.

KOVÀCS AM, MEHLER J. Cognitive gains in 7-month-old bilingual infants. PNAS Proceedings of the National Academy of Sciences of the United States of America.2009

KOVELMAN, I. et al. Bilingual and monolingual brains compared: a functional magnetic resonance imaging investigation of syntactic processing and a 284 possible "neural signature" of bilingualism. Journal of cognitive neuroscience, 153- 169, 2008.

MARTINS, M. G. L. Uma experiência de desenvolvimento de projetos didáticos na educação infantil bilíngue. USP, Faculdade de Educação, Dissertação de Mestrado. São Paulo, 2007

MECHELLI, A et al. Structural plasticity in the bilingual brain. Nature, 431, 757, 2004.

MEGALE, Antonieta Heyden. "Bilinguismo e Educação Bilíngue-Discutindo Conceitos". Revista Virtual de Estudos da Linguagem-ReVEL. V. 3, n. 5, agosto de 2005.

NOBRE, Alena Pimentel Mello; HODGES, Luciana Vasconcelos dos Santos. A relação bilinguismo-cognição no processo de alfabetização e letramento. Ciênc. cogn., Rio de Janeiro, v. 15, n. 3, p. 180-191, dez. 2010 .

PAAP, K., \& Greenberg, Z. (2013). There is no coherent evidence for a bilingual advantage in executive processing. Cognitive psychology, 232-258.

PERRI, Mariana. A alfabetização em escolas bilíngues: possibilidades e consequências, 2013. Disponível em: < http://pedagogiaaopedaletra.com/a-alfabetizacao-em-escolasbilingue-possibilidades-e-consequencias/>. Acesso em 10 de julho de 2016.

SANTOS, Thaís Cristine dos. A aquisição de uma segunda língua por crianças na educação infantil bilíngue. Universidade Estadual de Maringá. Maringá. Disponível em $:<$ http://www.dfe.uem.br/TCC-

2013/Trabalhos2013/THAIS_CRISTINE_SANTOS.pdf>Acesso em 12 de junho de 2016.

SILVA, Beatriz da. Desenvolvimento da linguagem:uma proposta inatista.Universidade Federal do Rio de Janeiro, 2011.

Disponível em: <

http://www.filologia.org.br/iiijnlflp/textos_completos/pdf/Desenvolvimento\%20da\%201 inguagem-\%20uma\%20proposta\%20inatista\%20-\%20BEATRIZ.pdf >. Acesso em 10 de julho de 2016. 
SELL, Sérgio. Chomsky $e$ o inatismo cartesiano. WORKING PAPERS EM LINGÜÍSTICA, UFSC, N.6, 2002

SUNDARA, M., Polka, L., \& Genesee, F. (2006). Language-experience facilitates discrimination of /d- $\mathrm{d} /$ in monolingual and bilingual acquisition of English. Cognition, 369-388.

UCCELLI, P., \& Paez, M. (2007). Narrative and vocabulary development of bilingual children from kindergarten to first grade: Developmental changes and associations among English and Spanish skills. Language, Speech, and Hearing Services in Schools, 225- 236.

YANG S; YANG H. Bilingual effects on deployment of the attention system in linguistically and culturally homogeneous children and adults. J Exp Child Psychol. 2016 Jun; 146:121-36.

YIN, R.K. Estudo de caso: planejamento e métodos. 3. ed. Porto Alegre: Bookman, 2005.

YOSHIDA $\mathrm{H}$ et al. Inhibition and adjective learning in bilingual and monolingual children. Frontiers in Developmental Psychology.2011;2:210.

TRASK, R. L. Dicionário de Linguagem e Linguística. São Paulo: Contexto, 2004 